\title{
Correction to: Broken Symmetry
}

\section{Correction to:}

\section{Chapter 3 in: L. Pismen, Morphogenesis Deconstructed, The Frontiers Collection, https://doi.org/10.1007/978-3-030-36814-2_3}

In the original version of the book, Fig. 3.5 has been replaced with revised figure in Chapter 3. The erratum chapter and the book have been updated with the change and approved by the author.
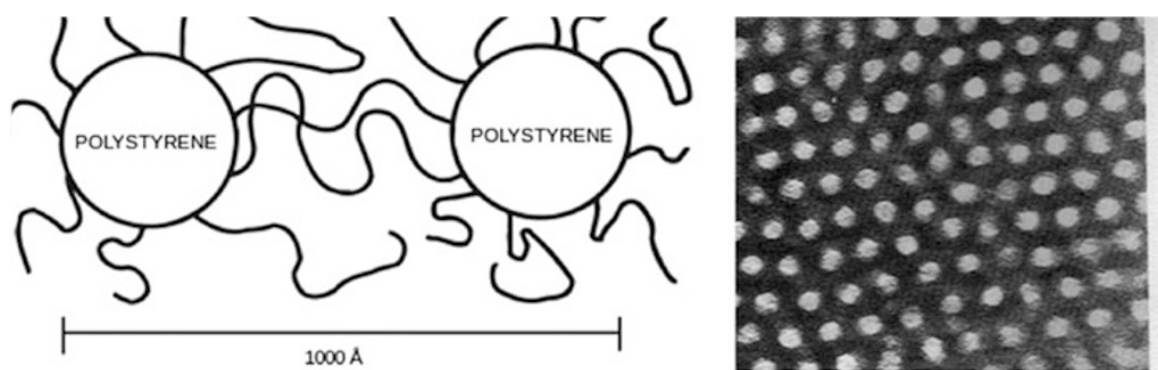

Fig. 3.5 Left: A scheme of separation of block copolymer units. Right: The resulting pattern

The updated version of this chapter can be found at https://doi.org/10.1007/978-3-030-36814-2_3 